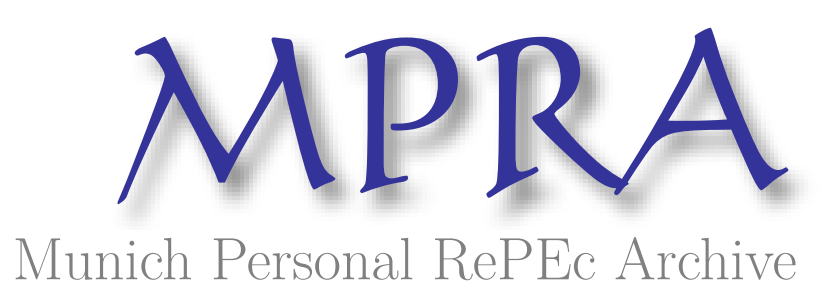

\title{
On the question of the relevance of Economics as a science: Postmodern filosofia critique
}

\author{
Jackson, Emerson Abraham \\ Bank of Sierra Leone, University of Birmingham
}

1 February 2018

Online at https://mpra.ub.uni-muenchen.de/86185/

MPRA Paper No. 86185, posted 13 Apr 2018 09:08 UTC 


\title{
On the question of the relevance of Economics as a science: Postmodern filosofia critique
}

\author{
Emerson Abraham Jackson ${ }^{12}$
}

\begin{abstract}
This article has adopted an open discourse in addressing pertinent concerns about the scientific existence of economics as a discipline. In doing so, some (critical) Filosofia arguments have been provided in ensuring that a well balanced approach is taken on the subject. Obviously, the approach of Popperian falsification used by economic science to address scientific justification through its varied scientific platform of technology applications like EVIEWS, STATA, MatLab and many more, have been applauded. Albeit such advances, the views of modern and postmodern critics have also come out saliently in a bid to ensuring open discourses are brought to the fore as a way of adding scientific value to the subject matter. In concluding, it was acknowledged that more is needed in ensuring that economic science as practiced by economists takes an open approach to critical discourse(s), reflecting reality about its pursed scientific ventures, given the persistence of economic volatility manifested across the global community.
\end{abstract}

Keywords: Economic Science; Scientific Methodology; Filosofia; Postmodern Critique

Jel Classification: $B 5, B 41$

\section{Introduction}

Economics, a derivative of the Greek term "Oikonomia" which started as a discipline in the social science field drifted around the early poetic writings of Hesiod (Rothbard, 1995: 8) towards being more of a quantitative science field; this was intended to study household management based on Aristotelian notion / doctrines (Eggleson, 2008: 4-5). Towards the end of the 18th century, the godfather of economics, Adam Smith emerged with a new coinage to the discipline titled 'Science of Wealth' (Smith, 1759 and 1776). While his idea of economics was still considered valid, Alfred Marshall, a popular English economist around the same era emerged with a definition to the concept as stated thus: "Economics is a study mankind in the

\footnotetext{
${ }^{1}$ Doctoral Research Scholar in Sustainable Livelihoods, Centre of West African Studies, University of Birmingham and Senior Research Economist, Bank of Sierra Leone.

${ }^{2}$ Disclaimer: Views expressed in this article are those of the Jackson(s) and do not reflect the official position of the named institutions.
} 
ordinary business of life" (McWilliams, 2008). This (definition) then extended the concept beyond the household to incorporate business cycle activities within an entire economic system, for example the household, firm and also government which is considered the main engine of economic activities.

As time progresses, thoughts around the concept were developing and most popular of this is that of Lionel Robbins, mostly referred to as the modern economist with his most widely used definition: "Economics is a science which studies human behavior as relationship between ends and scarce means which have alternatives uses" (Robbins,1932). According to the undermentioned excerpt, Robbins' idea was very much in place to develop constructive reasoning in view of dismal criticisms placed on the non-scientific base of the subject:

"It is a characteristic of scientific generalisations that they refer to reality. Whether they are cast in hypothetical or categorical form, they are distinguished from the propositions of pure logic and mathematics by the fact that in some sense their reference is to that which exists, or that which may exist, rather than to purely formal relations (1938: 343)."

As a practicing professional, the above is excerpt is very much encompassing as it addresses the scope for discourses that lend the subject matter towards being dynamically scientific, while at the same time addressing the need for the rationale being to judiciously rationalise scarce resources. One would simply argue that the filosofia element of the subject matter of economics is rooted from here, as it questioned the reasoning behind (economic) decisions made by agents, which are mostly dynamic in nature, even when one may come to look at its extensive study in relation to a typical 'ricardian and non-ricardian' DSGE modelling application of an entire economic system (Torres, 2012). The thirst for its scientific root can be thought of as being an epistemological journey as far as the situation is concerned in challenge of its critics about whether "economics is a science, pseudo-science or neither".

\section{Scientific Approach to Economic Science Research}

The (non)scientific discourses spanning the subject matter of economics will continue as an endless journey, in view of practitioners insistent in pursuing efforts to prove their (scientific) actions in a growing research environment. On this note, it is worthwhile taking a look at developments in model formulation ranging from Time Series, structural models like (S)VAR and more lately, DSGE used in justifying the power of empirical endeavours to model economic realities (Jackson et al, 2018, Jackson, forthcoming2, Bangura et al, 2012 and Torres, 2015). The claim on scientific evidence can be linked with the famous Popperian falsification argument on which sub-set of economics discipline like 'econometrics' have anchored its endeavours. Many a time, the effort to justify (apriori) theories in the economic science discipline is through arduous iteration during estimation and test procedures of data manipulation. 
Thanks to on-going developments in information technologies which is making it possible for scientific advances relating to model construction using simple technique like calibration in simulating economic realities. As a practicing (quantitative) economist, one may simply follow in the pathway, given the effort and time spent in making use of technology platforms like EVIEWS and many more to iterate around data provided in the process of testing established economic theories. Critics of quantitative economics may consider economic science(s) approach as a form of data massaging (Schrøder, 2012, Boland, 1977, Caldwell, 1984 and Machlup. 1955), which is equally the process applied in scientific laboratories by physical / natural scientists to justify the continued existence and reliance of established scientific theories; this in most cases may involve use of catalytic substances speed up substance-reaction in justifying outcomes of apriori (scientific) expectations.

\subsection{Falsification Arguments in Scientific Research}

Many economic scientists, particularly those interested in quantitative economic studies have developed positivist view of their actions to justify established theories through scientific test outcomes, which is aligned equally to that pursued in the physical / natural science(s) discipline. As a practicing economic researcher, one is sometime spun to choose between the acceptance of both normative and positivist view of the (non)scientific arguments of economics. In as much as Popper's approach to falsification is reigning sturdily in the area of economic research methodology, sporadic behaviours mostly displayed by economic agents meant that, truth about its scientific reality will continually be faced with dismal critiques. Boland's (1996) effort to advance critique on concepts around 'testability and falsifiability' in the economic science discipline is justifiably warranted, given the fact that economic theories will continually be faced with criticism on account of the pendulistic behaviour displayed by (economic) agents. This actually brings the notion of filosofia in the fore given the situation of rational decision economic agents are confronted with in utilising scarce resources

One may attest to supporting the claims of scientific procedures in the cause of hypothetical testing procedures during research undertakings, particularly when authentic historical data are used, and for which Boland (1991) termed as a form of social engineering in which policy makers are of the opinion that their policies may not easily be refuted, given the scientific linkage(s) of their policy outcomes. This does not always prove to be true when the reality is applied to economies in which economic agents' actions do not always follow the norm of established theories. So, the question of falsification argument may seem to be very much needed here as clarity in convincing critics about the insistence of economics direction as a science will need to be proved in all situations, for example through means like rational and irrational behaviour. 
Sometimes, one is also tempted to promote some thought provoking views, normally akin to be normative in nature around discourses of economics reality as a science as one continues to engage in practice. This for example have spanned from questions relating to thoughts spanning around heterodox views in economic research and to that of the notion of 'Criteris Paribus' as applied in a country like Sierra Leone, where a lot of the ills of (political) economy mismanagement and the pendulistic behaviour of economic agents seemed to be in contrary to one's own ontology as a quantitative economic scientist (Jackson, 2016, 2017 and forthcoming).

\subsection{Cases of Empirical Research as Evidences of Economics as a Scientific}

As clearly addressed in the Popperian philosophy of scientific approaches, the discipline of economic science which has lend itself towards proof of empirical research is dominating the profession and more so in research-based sections / divisions in central banks, policy tink-tank institutions and also universities across the world. There are myriad of test outcomes produced on a regular basis by researchers to justify claims of the scientific nature of economics, particularly in advancing knowledge, towards proving the continued existence of established (economic) theories or the development of new ontology of economic science's thinking.

In order to be able to argue this, it is worthwhile drawing reference to cases of the usefulness of economic science research in supporting critical thinking in areas like policy and academic advancement. To name a few, the Economic Modelling and Forecasting Group at the University of Warwick regularly makes use of econometric tools and supported by application platforms to pursue research ventures as a way of progressing economic science research in the academia, and the global community of practice and application of (empirical) economics. The high level of uncertainty in the global economy is actually making it much of a challenge posed on the validity of scientific outcomes produced in the field of economic science. Like any area of applied practice, the group seem to be making advances in terms of keeping up to date with research in the academia and economic policy through its link with the Bank of England, and also advances in the area of software development in support of scientific data usage [more so, historical] to validate decisions about economic outcomes. A noticeable case of such scientific practices to expand knowledge discourse in the field of economic science is that of Battisti et al (2007), who attempted to (partially) redress paucity of literature on the joint analysis of inter and intra firm diffusion of innovations within and as well as across countries; the application of "Bivariate Probit Mode" made it possible for data from independent country-specific surveys from the UK and Switzerland to unravel (international) comparison of inter and intra firm diffusion of Information and Communication Technology (ICT). Most important to this outcome is the dissemination of knowledge that has emerged out of such empirical investigation in promoting and exploring new ways of identifying robust relationships. Such outcome is spearheading related ventures in the direction of enhancing knowledge dissemination, much more so in the 
area of critical methodological discourses, and also its application to support policy decision in the real world of applied research (Ya-Ching Lee, 2010).

At the bank of Sierra Leone for example, research economists have over the past years and to date endeavoured to prove their efforts in support of the relevance of scientific economic theories to address the core objective of the bank, that is "maintain price stability". Work produced by Bangura et al (2012) for example, demonstrated scientific approach through their efforts in employing methodological procedure like Structural Vector Autoregression (SVAR) models to estimate pass-through effects of exchange rate to consumer prices in Sierra Leone. Econometric methodology tools used and supported by appropriate application platform like EVIEWS were sufficiently helpful in providing justified outcome to testify that exchange rate depreciation [due to economic agents' high dependence on foreign inflows] is a potential source of inflation in the Sierra Leone economy. Like any laboratory scientific experimentation, the philosophical intuition of such a study is highly based on series iterations, and for which those opposed to economic science methodology are normally quick to link it to data massaging.

Equally in the same year, Mansaray and Swaray (2012: 87) also made use of Granger-causality test methodology, which identified the presence of uni-directional causality running from real balances to inflation and real effective exchange rate respectively. One may claim in this case that the use of dummies used is akin to that of catalytic substances applied in most scientific laboratory experimentations, which is considered a justified means of scientific approach to support researchers' filosofia efforts in adding value to existing discourses spanning in the area of the scientific nature of economics. Equally, post-credit-crunch scientific research carried out by economist at the Bank of England, namely Joyce et al (2011) and Kapetanios et al (2012) made great strides in demonstrating the relevance of economic science's (methodological) endeavour in assessing the economy-wide effect of quantitative easing on asset pricing and longterm low interest rate in the UK; all of these were sufficiently greeted through the application of robust methodological procedures like 'Bayesian VAR and GARCH' in pursuance of scientific knowledge exploration.

One may come to the reality of complementing efforts made by economic researchers across the world, and particularly in central banks, despite ongoing criticisms in relation to the continued ir(rational) behaviour state of economic systems, which cannot directly be blamed on ignorance advanced by those opposed to economic science insistence as a science. As explained by Haldane (2016), the pressure of global financial threat and also critiques around the usefulness of economic science is in itself an essential element in making it possible for a rethink about the discipline's approach to scientific research, either in the way of embracing others or in cognisance of the social realm in which economics as a discipline is rooted. The above [critique] is not sufficient to stop research ventures in economics coming to a halt as research efforts by scholars like Joyce et al (2011) and Kapetanios et al (2011) were considered useful in addressing 
pertinent development in the advancement of knowledge exploration towards assessing the impact of quantitative easing since the last global financial crash between 2007/09. In a similar token, the application of scientific methodologies like ARIMA[X], SARIMA and many more continue to prove their scientific ground as applied more lately by various researchers to address discourses in the area of 'in and out-of-sample forecast' on inflation dynamics and its exogenous determinants for policy decision at central banks (Jackson et al, 2018, Ericsson, 2016, Erik et al, 2013), and also in industrial / professional endeavours as applied by Bigovic (2012).

The above highlight of varied scientific approaches used in the justification of economics as a science discipline cannot remain complacent given the dynamic nature of the social realm in which the subject matter rest. In this regard, there is a need for researchers in the discipline to be more receptive to their critics, simply on the basis of accommodating the development of new thoughts in addressing global occurrences. Despite critiques levied on the more recent approach to DSGE modelling, it is still perceived as an ideal scientific model in allowing economic systems to be modelled through simulation technique, with and without data usage (Torres, 2015).

\section{Contemporary and Postmodern Critical Discourses}

Some economists like Crespo (1998) and Hodgson (2008) have questioned the morality and ethical value of the scientific base of economic science; to Crespo in particular, economic science is considered a practical science that should seek to direct human epistemology into addressing practical realities of life. In the journey of methodological approaches used by quantitative economists, it may seem as if models are mostly used to justify the continued existence of established (economic) theories as opposed to creating practical realities on how economic agents (can) adjust to things happening in their surroundings. In contrast to Friedman's (1953) dogmatic notion of precision about economic model forecast outcomes, Hodgson (2008) was able to provide alternative perspective, especially around complex phenomenon and nonlinear interaction about the limited scope for prediction and for which science must endeavour to explain outcomes based on causal relationships.

Critical discourses is resounding all around the world and even amongst hard-core practicing economists about the direction of economics (and particularly models) in its continued insistence about its scientific procedures, rather than concentrating on the practical realities of its engagement with the social realm; one such critic is Blaug (1997) who on quote stated:

"Modern economics is sick - Economics has increasingly become an intellectual game played for its own sake and not for its practical consequences for understanding the economic world. Economists have converted the subject into a sort of social mathematics in which analytical rigour is everything and practical relevance is nothing". 
In his book titled "The Methodology of Economics or how economist explain it", Blaug (1997) provided a clear, but more so, thought provoking discourses around the insistence of economics and its alignment with the physical science - he considered the discipline to be plagued with mathematical concepts, but rather weak in its reality to the social realm in the subject is meant to be applied.

To many, and not only those in the present or modern society, economic science seem to have embraced itself with mathematical modelling rather than on the practical realities on which human decisions are meant to be focused (Knight 1921, Keynes 1937); to many of these critics, models are thought to be very limited in their scope to address issues of pertinent concern to the human race, which are mostly considered to be unpredictable. On a similar critical viewpoint, Kirman (1992) noted that our understanding of economic phenomena cannot be adequately realised without taking into consideration the diversity within populations of human characteristics and dispositions. This is an area of critical importance when it comes to justifying economic models outcome, without much cognisance of the varied economic systems and cultures people are exposed to around the world; some of the practicing systems are thought to be existing in a mere perfect market environment, while some are just too imperfect to enable sound judgements to be made about economic model applications (Jackson, 2017). This then puts limit on the use of mathematical modelling to address and deal with real situations, despite efforts made by some model proponents in applying intuition to support policy prescription (Torres, 2015). More recently, published works of modern Economic Scientist like Boland (2014: 124) have questioned the unsolved puzzles and performances of econometric-based forecasting models; to him, econometric models are meant to be a 'shot at the real target' and which does not really work for two category of reasons: "(1) it was a 'bad' shot -that is, the model was logically invalid or empirically false - or (2) the target moved - that is, there was random unexplained variation in the objects the model is designed to explain (p. 126).

Postmodern thoughts involving the practice of economics have taken varied views on the practice and application of the subject matter, particularly its approach to scientific alignment and also in relation on how it is practiced, given the motive of models to shape economic realities. Klamer and McCloskey (1989: 4) and more lately, Ruccio (1991: 496) have argued their critical points, not only based on disagreement spanning around economic issues and politics, but most importantly on the mechanical and scientistic notion relating to the 'doings of economists'. There is the notion of dichotomy spanning around uncertainty amongst myriad of models on which neoclassical views are based. According to Ruccio (1991: 505), it is thought that economists have avoided the nihilistic approach to postmodern critique spanning the notion of uncertainty, while dogging in the direction of less probabilistic uncertainty and rational expectations. Such criticism is rather placed between value and science, and also the role of mathematics in addressing issues of concern to the postmodern critics on the subjective approach to its modernistic practice. 
Postmodern thinkers like Warren Samuels (1990) have argued in favour of a turn from the modern notion of theoretical models to that of 'Critical Discourse Analysis and Critical Realism' as emphasised in a working paper produced by Boland $(\mathrm{n} / \mathrm{d})$ to address situations of scientific theories - to him, there is scope to re(construct) established theories in a bid to reshape situations in economic science. In this way, the acclaimed application of universal methodology of economic science can be viewed from "eclectic and agonistic point", and also the use of metaphors, which is not only restricted to communication and teachings, but more so on the cognitive content of theories. In moving on with critical discourses surrounding the direction and scientific nature of economics, Ruccio (1991: 508) highlighted some pertinent questions in view of the critical postmodern thinker:

- Can the notion of scientific argumentation within economics be opened up to include the rhetorical and figurative dimensions of discourse? What, then, is the role of mathematical models, axiomatic logic, and other -formal| modes of persuasion?

- What remains of the discipline of economics if it contains incommensurable theories and discourses? What are the conditions for conversation among economists? And what is the relationship of economics to other areas of human thought, including literature?

- Does economics have a responsibility to consider the effects of the (non)rational and irrational - the economy of desire, the will to power - on rationality? What about the discursive constitution of rationality - "animal spirits" and expectations? Is there a position for the decentered subject within economics?

- Can economics endure the disruptive effects of time? Is it possible to displace master binary oppositions such as equilibrium / disequilibrium and to move economic analysis outside equilibrium?

The above are considered thought provoking questions in the direction of the future of economic science, which also takes cognisance of its social science root. In this regard, thoughts should be spanning around incorporating wider notion of the social realm in which the subject matter lies, rather than its insistence in shaping complex mathematical models, with very little scope for intuition on how (ir)rational behaviour of (economic) agents may affect outcomes.

In digressing further on this, the views of new-comers in the economics profession like feminist economists, development economists and also ecological economists would also attest to the complex and varied models to satisfy its scientific base, mainly as a way of appeasing those of its critics about its pseudo or non-scientific base. The conception of 'homo-economicus' is an area that has been of contention around feminist view of their exclusion when it comes to economic model construction; this to the many feminist and also supporters of feminist movement have made it very difficult for rational discourses to be debated around women's contribution on the debate in making their cases for the advancement of scientific contribution to the subject matter (Nelson, 1991). 
On a similar note, development economists have equally provided their (postmodern) thoughts in the area of methodological advances pertaining to the need for a rethink on economic science's approach, more so connected with the applicability of theories to different economic situations (Jackson, forthcoming3). It is but certain that the practice of economic science and its methodological approach will need to consider embracing postmodern views around dynamism in economic situations, and for which the practicalities of models in developing country's context can be very less applicable or irrelevant given the imperfect conditions prevalent in their market systems.

\section{Conclusion and the way forward}

In all fairness, economic science has come a long way in terms of aligning itself with mainstream traditional scientific disciplines, and more so affirming its recognition through the application of Popper's doctrine of falsification. The dominance of numerical contents to address complex economic models is one of great concern to modern critics and also, postmodern thinkers in the discipline. As a practicing economist, one may be inclined to subscribe to the discourse of critical views given the generalistic notion and difficulties associated adapting models to less complex economic systems. Economic science as practiced in developed economies can be argued in the direction of proving its scientific dogma given the fact that model applications can be reasonably well tested with (near) accurate and authentic data. In the context of developing countries, particularly Sierra Leone, where data accessibility is difficult to come by and also, added to the pendulistic behaviours manifested by economic agents, it is almost impossible for economics to prove its scientific base in the affirmation of established economic theories. This makes it quite difficult for test outcomes to be proved valid the use of varied and incompatible data can easily render theories non-generalisable.

On a positive note, the practice of economic science has come a long way and particularly through advancement in technology to handle (complex) data manipulation in testing theories through its (laboratory) platform of varied technology applications. Such developments have made it possible for epistemological progress to be made in terms of the applicability of theories to economic policies and also new developments in thoughts pertaining to future progress in the discipline. Moving on, there is a need for consensus in the direction of embracing both modern and postmodern views in order to make the discipline less susceptible to dismal criticisms. In this situation, it is possible that concept around 'critical realism' can be a considered methodological approach in addressing discourses around ways of developing the applicability of established models to support economic advances on how to challenge economic malaise around the world. As stated by Viktor (1981), modern economics should consider diverting attention to embracing qualitative analysis, in addition to quantitative data manipulation, given the fact that even the most sophisticated of quantitative econometric models were not sufficient to prevent an economic crash as witnessed around 2007-09. 


\section{References}

Bangura, M., Caulker, E. and Pessima, S. (2012). Exchange Rate Pass-Through to Inflation in Sierra Leone: A Structural Vector Autoregressive Approach. Journal of Monetary and Economic Integration, 12(1), 93-123.

Barber, W. 1967. A History of Economic Thought. Harmondsworth: Penguin Books.

Blaug, Mark (1997) 'Ugly Currents in Modern Economics', Options Politiques, 18(17), September, pp. 3-8. Reprinted in Mäki, Uskali (ed.) (2002) Fact and Fiction in Economics: Models, Realism and Social Construction (Cambridge and New York: Cambridge University Press).

Boland, LA. (1977). Testability in economic science, So. African Journal of Economics, 45(1977), 93-105.

Battisti, G., Hollenstein, H., Stoneman, P and Woerter, M. (2007). INTER AND INTRA FIRM DIFFUSION OF ICT IN THE UNITED KINGDOM (UK) AND SWITZERLAND (CH) AN INTERNATIONALLY COMPARATIVE STUDY BASED ON FIRM-LEVEL DATA, Economics of Innovation and New Technology, 16(8), 669-687. DOI: 10.1080/10438590600984026.

Bigovic, M. (2012). Demand forecasting within Montenegrin tourism using Box-Jenkins methodology for seasonal ARIMA models. Tourism and Hospitality Management, 18(1), 1-18.

Blaug, M. (1997 ed). THE METHODOLOGY OF ECONOMICS or how economists explain it. UK: Cambridge University Press.

Boland, L. (n/d). Critical Realism vs Economic Rhetoric. Working Paper, Simon Fraser University. Retrieved from: http://www.sfu.ca/ boland/realism.htm. (Accessed: $5^{\text {th }}$ March, 2018).

Boland, L. (2014). Model Building in Economics: Its Purposes and Limitations. Cambridge: Cambridge University Press.

Boland, LA. (1996). Critical Economic Methodology - A Personal Odyssey. Routledge: London and New York.

Boland, LA. (1991). Current Views on Economic Positivism. Companion to contemporary economic thought. 
Caldwell, BJ. (1984). Some Problems with Falsificationism in Economics. Philosophy of the Social Sciences, 15(4), 489-495. DOI: 10.1177/004839318401400404.

Crespo, R.F. (1998). Controversy: Is Economics a Moral Science? Journal of Markets \& Morality, 1(2), 201-211.

Eggleston, Brian. 2008. Economics and/as Ethics: From Aristotle to Adam to Arrow. Augustana College. Retrieved from: http://www.augie.edu/pub/values/BrianEggleston080310.pdf. (Accessed: 1st March, 2018).

Ericsson, Neil R. (2016). Economic Forecasting in Theory and Practice: An Interview with David F. Hendry. International Finance Discussion Papers 1184. DOI: 10.17016/IFDP.2016.1184.

Etuk, E.H., Moffat, I.U and Chims, B.E. (2013). Modelling Monthly Rainfall Data of Port Harcourt, Nigeria by Seasonal Box-Jenkins Methods. International Journal of Science, 2 (Juy), 60-67.

Friedman, Milton (1953) 'The Methodology of Positive Economics', in M. Friedman, Essays in Positive Economics, Chicago: University of Chicago Press.

Galbraith, J. 1977. The Age of Uncertainty. Boston: Houghton Mifflin.

Haldane, A.G. (2016). The Dappled World. Retrieved from: http://www.bankofengland.co.ukpublications/Documents/Speeches2016/speech937.pdf. (Accessed: $1^{\text {st }}$ March, 2018).

Heilbroner, R. 1986. The Worldly Philosophers. Sixth edition. London: Penguin Books.

Hodgson, G., (2008b) What is Wrong with Mainstream Economics? And How Could Economics be Improved? Retrieved from: http://www.feed-charity.org/our-differences-withmainstreameconomics.htm. (Accessed: $2^{\text {nd }}$ March, 2018).

Jackson, E.A., Sillah, A. and Tamuke, E. (2018). Modelling Monthly Headline Consumer Price Index (HCPI) through Seasonal Box-Jenkins Methodology. International Journal of sciences, 7(1), 51-56. DOI: 10.18483/ijSci.1507.

Jackson, E.A. (forthcoming). Triangulation: A Retroduction Approach in the Reorientation of Social Science Research for Central Bank Policy in Sierra Leone. 
Jackson, E.A. (forthcoming2). Introduction to Dynamic Macroeconomic General Equilibrium Models (2nd Ed), 282p. ISBN: 978-1-62273-030-8 (Hardcover, by: Josh L. Torres).

Jackson, E.A. (forthcoming3). Research Methodology in the Social Sciences: Perspective on Sierra Leone.

Jackson, E.A. (2016). Ontological and Epistemological Discourse(s) on Sustainable Development: Perspective on Sierra Leone in the Aftermath of a Decade of Civil Unrest. Journal of Management and Sustainable Development, 8(1), 35-43. DOI: 10.1515/msd-2016-0005.

Jackson, E.A. (2017). Economic Methodology: Paradox of Ceteris Paribus (CP) Law in the Context of Sierra Leone. Method(e)s: African Review of Social Sciences Methodology, 2(1-2), 31-4. DOI: 10.1080/23754745.2017.1354553.

Joyce, M.A.S., Lasaosa, A., Stevens, I., and Tong, M. (2011). The Financial Market Impact of Quantitative Easing in the United Kingdom. International Journal of Central Banking, 7(3), 113161.

Kapetanios, G., Mumtaz, H., Stevens, I., and Theodoridis, K. (2012). Assessing the economy-wide effects of quantitative easing. The Economic Journal, 122(564), F316 - F347. DOI: $10.1111 / \mathrm{j} .1468-0297.2012 .02555 . x$.

Keynes, John Maynard (1937) "The General Theory of Employment", Quarterly Journal of Economics, 51(1), 209-23.

Kirman, Alan P. (1992). Whom or What Does the Representative Individual Represent? Journal of Economic Perspectives, 6(2), 117-36.

Klamer, A. and McCloskey, D. (1989). "The Rhetoric of Disagreement" - Rethinking Marxism, 1989(2), 140-162.

Knight, F.H. (1921) Risk, Uncertainty and Profit. New York: Houghton Mifflin.

Lee, Ya-Ching. (2010) Business Process Reengineering Within the Media Industry in Taiwan. International Journal on Media Management 12:2, 77-91.

Machlup. F. (1955) 'The Problem of Verification in Economics', Southern Economic Journal, 21. $1-21$.

McWilliams T.R. (2008). "Alfred Marshall (1842-1924)". Oxford Dictionary of National Biography, OUP. DOI:10.1093/ref:odnb/34893. 
Mansaray, M. and Swaray, S. (2012). FINANCIAL LIBERALIZATION, MONETARY POLICY AND MONEY DEMAND IN SIERRA LEONE. Journal of Monetary and Economic Integration, 12(2), 62-90.

Nelson, J.A. (1991). Feminism and Economics. Journal of Economic Perspectives, 9(2), 131-148.

Robbins, L. (1932). AN ESSAY ON THE NATURE AND SIGNIFICANCE OF ECONOMIC SCIENCE. London: MACMILLAN and CO., LIMITED.

Robbins, L. (1938). Live and Dead Issues in the Methodology of Economics. Economica, New Series, 5(19), 342-352.

Rothbard, MN. (1995). Economic Thought Before Adam Smith: Austrian Perspective on the History of Economic Thought. UK: Edward Elgar Publishing.

Ruccio, D. (1991). Postmodernism and Economics. Journal of Post-Keynesian Economics, 13(4), 495-510.

Samuels, W.J. (1990). Economics as Discourse: An Analysis of the Language of Economists. Boston: Kluwer.

Schrøder, K. C. 2012. "Methodological pluralism as a vehicle of qualitative generalization." Journal of Audience \& Reception Studies 9 (2), 798-825.

Smith, A. (1759). The Theory of Moral Sentiments. Mineola, New York: Dover Publications.

Smith, A. (1776). An Inquiry into the Nature and Causes of the Wealth of Nations (The Wealth of Nations). Oxford: Oxford University Press.

Torres, J.L. (2015). Introduction to Dynamic Macroeconomic General Equilibrium Models. USA and Spain: Vernon Press.

Vikor, D. (1981) "Toward Qualitative Economic Analysis", International Journal of Social Economics, 8(7), 42-49. DOI: 10.1108/eb013901. 